\title{
Migração e qualidade de vida: um estudo psicossocial com brasileiros migrantes
}

\author{
Migration and quality of life: a psychosocial \\ study of Brazilian migrants
}

\author{
leda FRANKEN ${ }^{1,2}$ \\ Maria da Penha de Lima COUTINHO \\ Natália RAMOS ${ }^{3}$
}

\section{Resumo}

Objetivou-se estudar as representações sociais de 51 brasileiros, 37 do sexo feminino e 14 do sexo masculino, migrantes residentes na cidade de Genebra, Suiça, sobre qualidade de vida e migração. Utilizou-se um teste de associação livre de palavras. Os dados apreendidos foram processados pelo software Tri-Deux-Mots e analisados por meio da análise fatorial de correspondência. Os resultados evidenciaram que as variáveis sexo e tempo de migração contribuíram com valores mais elevados para o significado dos fatores. Observaram-se nos diferentes grupos similitudes e diferenças de conteúdos representacionais, que colocam em evidência uma comunicação e orientação de condutas de acordo com as variáveis sociodemográficas circunscritas, favorecendo sua identidade e comprovando sua função justificadora.

Unitermos: Migrações. Qualidade de vida. Representações sociais.

\begin{abstract}
The objective of this study was to analyze the social representations of 51 Brazilian immigrants (73\% female and 27\% male) living in the city of Geneva, Switzerland, about the quality of life and migration. The free word association test was employed. The data collected were processed by the software Tri-Deux-Mots, and were analyzed using Factorial Correspondence Analysis. The results showed that the variables of gender and period of migration contributed with higher values for the meaning of the factors. The similarities and differences in the representational content were observed in the different groups, which evidenced a communication and orientation of behavior according to the socio-demographic variables established, benefiting their identity and testifying to their justifying function.
\end{abstract}

Uniterms:Migrations. Quality of life. Social representations.

A complexidade do mundo moderno, o capitalismo e o desenvolvimento tecnológico aprimoram cada vez mais as técnicas de produção, ampliam mercados, modificam postos de trabalho e provocam a expansão de necessidades de consumo, acarretando irreversíveis modificações na vida das pessoas. Em

\section{$\boldsymbol{\nabla \nabla \nabla \nabla}$}

1 Universidade Federal da Paraíba, Programa de Pós-Graduação de Psicologia, Núcleo de Pesquisa Aspectos Psicossociais de Prevenção e Saúde Coletiva. Conjunto Humanístico, Bloco IV, Campus I, Cidade Universitária, 58059-900, João Pessoa, PB, Brasil. Correspondência para/Correspondence to: M.P.L. COUTINHO.

2 Doutoranda em Psicologia Clínica e da Saúde, Universidade Aberta de Lisboa. Lisboa, Portugal.

3 Universidade Aberta de Lisboa, Núcleo de Estudos sobre Migrações e Relações Interculturais. Lisboa, Portugal. 
função desta produção, destes mercados e da globalização, sacrificam-se os referenciais humanos e suas integridades psicológicas, o que determina, muitas vezes, o deslocamento das pessoas para novos centros de trabalhos, provocando fenômenos sociais como: o êxodo rural, migrações internas e internacionais, em busca de viver com melhor qualidade de vida (Ramos, 2004).

Todos os países desenvolvidos ou em desenvolvimento estão imersos no fenômeno da globalização (Hogo, 1998); com isso, tem-se registrado um acentuado movimento de populações das regiões desfavorecidas para as mais industrializadas, e as regiões menos desenvolvidas são caracterizadas por índices de subdesenvolvimento crônicos, que é a principal gênese dos fluxos migratórios internacionais. Altos níveis de desemprego e pobreza, deficientes sistemas de saúde e ensino instigam nas populações dessas regiões o desejo de procurar melhor sorte em outras regiões mais ricas do globo (Seabra, 2003). Segundo Arnold (1995), mais da metade dos países que recebem imigrantes está localizada em regiões muito desenvolvidas.

As experiências de sociedades avançadas, como as da Suíça, Portugal e França, que possuem uma trajetória migratória intensa, confirmam o caráter sócio-histórico e estrutural da migração. A Suiça do século XIX foi um país de migrantes, porém após a Segunda Guerra Mundial o saldo imigratório tem sido constantemente positivo. A necessidade de mão de obra estrangeira para atender às necessidades de desenvolvimento fez da Suíça um país de grande atração para os estrangeiros. No final do século XX, com o estabelecimento da Comunidade Europeia, intensificaram-se os movimentos migratórios em todos os países da Europa. E, na Suíça, apesar de não participar da Comunidade Europeia, observa-se um significativo aumento no contingente de imigrantes de diferentes nacionalidades.

O Relatório sobre a Divisão de População das Nações Unidas (UNFPA, 2007) menciona que atualmente há 191 milhões de migrantes no mundo; destes, 94,5 milhões são mulheres, que deixam seu país levando no imaginário a possibilidade de alcançar uma melhor qualidade de vida para si e para os seus. Esta maior visibilidade das mulheres nas migrações internacionais recentes contribuiu para problematizar as visões crista420 lizadas sobre a inserção de homens e mulheres mi- grantes neste processo, evidenciando questões de como se rearticulam as relações de gênero e a tônica da busca de melhores condições de vida que os centros mais desenvolvidos possam Ihes oferecer.

Os dados oficiais da Organisation de Cooperation et de Developpement Économique (OCDE) (2005) mostram que, a cada ano, 2,5 a 4 milhões de migrantes atravessam as fronteiras internacionais sem autorização. Em 2000, pelo menos cinco milhões dos 56,1 milhões de migrantes, na Europa, estavam em situação irregular. Estima-se que 500 mil migrantes sem papéis chegam à Europa a cada ano. Segundo dados da Organisation for Economic Co-Operation and Development Système D'Observation Permanente des Migrations International (SOPEMI) (2008), a imigração legal de tipo permanente de estrangeiros (cerca de quatro milhões) continuou a aumentar em 2006, um aumento de cerca de 5\% em relação a 2005.

Na Suíça, os 1,1 milhões de estrangeiros constituíam, em 1990, um índice de 16\% da população; a proporção de estrangeiros nesse país, contando todas as nacionalidades, subiu de 14\% em 1980 para 21\% em 2003 (Jimènez, 2005).

Na cidade de Genebra, registra-se uma população de 414 mil habitantes; destes, 158 mil são estrangeiros (38\%). Estima-se que 18 mil são imigrantes sem papéis oriundos da América Latina (Optical Fibre Sensors - OFS, 2008).

Embora dados sobre a população migrante sejam publicados por organismos internacionais, parece importante salientar que carregam na sua informação dificuldades de aferição e imprecisões, visto que muitos indivíduos que migram à procura de melhores condições de vida - os deserdados do capitalismo, em sua maioria - não figuram nas estatísticas oficiais como migrantes, mas como turistas.

No tocante à população brasileira no exterior, esta ainda não foi alvo de um levantamento oficial, mas as estimativas de pesquisadores do assunto apontam para números elevados. No final da década de 1990 havia cerca de três milhões de brasileiros morando em outros países, e calculava-se que em torno de 33\% estavam clandestinamente nos países de acolhimento. Essas informações são corroboradas por Sebe (2004), ao aludir ser possível que a população brasileira no exterior chegue a cinco milhões de pessoas. 
Essas premissas podem ser empiricamente identificadas em uma visita à cidade de Genebra, na Suíça, onde se observa a presença marcante de brasileiros nos mais variados ambientes públicos, como meios de transporte, comércio, bares, supermercados etc. Parece certo que muitos brasileiros vivem nesta cidade. Porém, o Instituto Brasileiro de Geografia e Estatística (IBGE), no Brasil, e também o Centre de Contact Suisses-Immigrés (CCSI), na cidade de Genebra, não possuem informações baseadas em estudos científicos, quer seja sobre dados demográficos ou sobre a qualidade de vida desta população.

\section{Qualidade de vida}

Embora encerre um conceito relativamente recente, a expressão "qualidade de vida"é, hoje em dia, utilizada frequentemente, quer ao nível da linguagem comum, quer ao nível do discurso teórico; é um tema central em todas as análises e políticas de planejamento e gestão. Tem sido um dos conceitos mais discutidos e existe certa dificuldade em se chegar a um acordo quanto ao que realmente significa. Tal dificuldade parece estar relacionada ao fato de se perceber que o significado deste conceito varia de uma cultura para outra, de um indivíduo para outro, e em tempos diferentes (Minayo, 2000). Minayo refere que esta relatividade remete à noção de qualidade de vida no plano individual e também a três fóruns de referência. O primeiro é histórico, ou seja, em determinado tempo o desenvolvimento econômico, social e tecnológico de uma sociedade específica possui um parâmetro de qualidade de vida diferente da mesma sociedade em outra etapa histórica. O segundo é cultural: valores e necessidades são construídos e hierarquizados diferentemente pelos povos, revelando suas tradições. O terceiro aspecto se refere às estratificações ou classes sociais.

Lobo e Santos (2002), Nussbau (1993) e Setién (1993) analisam as sociedades em que as desigualdades e heterogeniedades são muito fortes e mostram que os padrões e as concepções de bem-estar são também estratificados, isto é, a ideia de qualidade de vida está relacionada às camadas superiores e à passagem de um limiar a outro. Para a Organização Mundial de Saúde - OMS (2002), a qualidade de vida é um conceito holístico que reúne o conjunto de recursos sociais, individuais e físicos necessários ao indivíduo para a realização dos seus objetivos e aspirações, bem como para a satisfação das suas necessidades em diferentes níveis.

De acordo com M. Kurtz, Wyatt e J.C. Kurtz (1995) e Harding et al. (1980), as dimensões da qualidade de vida incluem a saúde física e mental, a integração social, a moradia, o tempo livre, o lazer, a educação, o ambiente, as relações interpessoais e o bem-estar geral. Auray e Duru (1995) e Witier (1997) aludem que qualidade de vida não é o reflexo direto das condições reais e objetivas da vida das pessoas, mas da avaliação que cada uma faz a respeito dessas condições, envolvendo assim elementos subjetivos e objetivos.

Pesquisas sobre qualidade de vida apontam para valores não materiais, como amor, liberdade, solidariedade, inserção social, realização pessoal e felicidade; e também a elementos materiais, que têm como referência noções relativas de conforto, bem-estar e realização individual e coletiva, como alimentação, acesso à água potável, habitação, trabalho, educação, saúde e lazer. É possível dizer que desemprego, exclusão social e violência são, de forma objetiva, reconhecidos como a antítese da qualidade de vida. Trata-se, portanto, de componentes passíveis de mensuração e comparação, mesmo levando-se em conta a necessidade permanente de relativizá-los culturalmente no tempo e espaço (Minayo, 2000). Ainda segundo o pensamento desta autora, qualidade de vida é uma noção eminentemente humana, que tem sido aproximada ao grau de satisfação encontrada na vida familiar, amorosa, social e ambiental, assim como à própria estética existencial. Pressupõe a capacidade de efetuar uma síntese cultural de todos os elementos que determinada sociedade considera padrão de conforto e bem-estar; é, portanto, uma construção social com a marca da relatividade cultural.

Muitos outros autores têm oferecido outras formas de conceituar qualidade de vida, e as investigações geram mais e mais definições. Nos últimos anos, parece mais útil o estudo de seu componente subjetivo, de sua natureza psicológica avaliada pelo próprio indivíduo (Bonomi, Patrick, Bushnell \& Martin 2000; Fayers, 2000; Pachoal, 2000).

\section{Representações sociais}

Moscovici (2003) afirma que a noção de representação social possibilita compreender como os 
indivíduos apreendem os acontecimentos da vida comum, os dados do ambiente, as informações que circulam, bem como apreender os pensamentos, sentimentos e experiências de vida compartilhada, através de diferentes modalidades de comunicação, representações estas diretamente relacionadas ao contexto social no qual vivem. Ainda segundo Moscovici (1981), a representação social é compreendida como "um conjunto de conceitos, afirmações e explicações originadas no decurso do cotidiano e no decurso das comunicações interindividuais" (p.181).

Todos os fenômenos que emergem do contexto social são investidos simbolicamente e recebem nomes e significados que os avaliam, explicam e Ihes dão sentido. Assim, o processo migratório, que faz parte do cotidiano social, recebe significados desde os mais longínquos tempos. Esses significados, à medida que circulam, transformam-se e assumem formas diferentes, de acordo com os modelos vigentes em uma determinada época e formação social. Ademais, são resultantes da interação entre os dois universos: o consensual associado ao conhecimento cotidiano e o reificado ao conhecimento científico, culminando em uma diversidade de significados sobre o processo migratório e a qualidade de vida que circulam através dos meios de comunicação formais e informais, assimilados e reelaborados socialmente (Coutinho, 2001; Coutinho \& Saldanha, 2005).

Nóbrega (2001), ao referir sobre os aspectos constituintes da representação, explica que tais aspectos envolvem a imbricação e a articulação entre atividade cognitiva e as condições sociais em que são forjadas as representações. Os aspectos constituintes são: a objetivação, que consiste em materializar as abstrações, corporificar os pensamentos, tornar físico e visível o impalpável, enfim, transformar em objeto o que é representado; e a ancoragem, que permite a incorporação do desconhecido ou novo em uma rede de categorias usuais.

Para Vala e Monteiro (2005), a objetivação diz respeito à forma como se organizam os elementos constituintes da representação e ao percurso através dos quais tais elementos adquirem materialidade e se tornam expressões de uma realidade pensada como natural. A ancoragem refere-se ao fato de qualquer 422 construção ou tratamento de informação exigir pontos de referência. Quando um indivíduo pensa um objeto, seu universo mental não é, por definição, tabula rasa; pelo contrário, é com base em experiências e esquemas de pensamentos já estabelecidos que um objeto novo pode ser pensado.

Como analisa Moscovici, se a objetivação explica como os elementos representados de uma teoria se integram enquanto termos da realidade social, a ancoragem permite compreender a maneira pela qual eles contribuem para exprimir e constituir as relações sociais (Abric, 1994; Moscovici, 1978).

Este trabalho objetivou estudar a representação social da qualidade de vida e da migração com uma população de brasileiros migrantes que escolheram a cidade de Genebra, na Suíça, como local de acolhimento.

Segundo Coutinho e Saldanha (2005), estudar a qualidade de vida no contexto migratório na perspectiva psicossociológica ancorada nas Representações Sociais (RS) significa estudá-la não apenas por meio de teorizações e normatizações científicas, mas com vistas a um novo olhar, voltado para a construção de um conhecimento prático e compartilhado por um determinado grupo de pertença. Deste modo, as representações sociais podem ser entendidas como produtos de atividades psicossociais autônomas, próprias de uma sociedade e de determinada cultura. Para Di Giacomo (1986), são modos de conhecimento e de processos simbólicos estudados em relação com as culturas, nas quais o indivíduo é direta ou indiretamente produto e produtor cultural.

\section{Método}

Neste estudo, a constituição da amostra seguiu o critério da técnica de amostragem não probabilística: a partir da população já conhecida foram identificados outros participantes da mesma população. Desta forma, foi alcançado um total de 51 imigrantes brasileiros residentes há mais de um ano na cidade de Genebra, Suiça; destes, 37 eram do sexo feminino. A inclusão dos participantes na constituição da amostra obedeceu aos seguintes critérios: aceitar participar do estudo de forma anônima e voluntária; ter idade acima de 18 anos; estar residindo na cidade de Genebra há mais de um ano. 
O procedimento ético foi assegurado pelo parecer n 570/2007 da Comissão Nacional de Ética em Pesquisa do Ministério da Saúde; posteriormente, foram explicitados junto aos atores sociais os objetivos, a relevância social e a segurança do sigilo de sua identidade.

Os instrumentos de coleta de dados utilizados foram um questionário sociodemográfico e a técnica de associação livre de palavras. Esta foi adaptada, no campo da psicologia social, por Di Giacomo (1986), e desde então vem sendo amplamente utilizada nas pesquisas sobre as representações sociais. Trata-se de uma técnica semiestruturada constituída de estímulos indutores, verbais ou iconográficos, e que, na pesquisa aqui descrita, foi estruturada a partir de dois estímulos: imigração e qualidade de vida. Estes foram colocados alternadamente em ordens de aparecimento, para anular o efeito de contágio nas respostas (Nóbrega, 2003). A questão colocada, para cada estímulo, consistiu em solicitar aos participantes que escrevessem as palavras ou expressões verbais que mais rapidamente thes ocorriam à mente quando anunciado o estímulo.

Os dados coletados pela técnica de associação livre foram processados pelo software Tri-Deux-Mots (Cibois, 1991), versão 2.2, que permite a visualização gráfica tanto das variáveis fixas como das de opinião, e analisados por meio da Análise Fatorial de Correspondência (AFC). A AFC é um procedimento estatístico que consiste em distinguir os vínculos estabelecidos entre as características dos indivíduos que constituem um grupo e suas respostas a uma determinada questão.

\section{Resultados}

Após o processamento dos dados do questionário biossociodemográfico, os resultados apontaram que, entre o total das participantes do sexo feminino, 29,7\% residiam na cidade de Genebra há um período de um a três anos; 70,3\% apresentaram tempo de residência superior a três anos; $45,9 \%$ eram possuidoras de migração documentada; e 54,1\% eram imigrantes não documentadas. Quanto ao sexo masculino, 57,2\% residiam na cidade de Genebra há um período de um a três anos; $42,8 \%$ tinham tempo de residência superior a três anos; destes, 28,5\% eram imigrantes documentados e 71,5\% viviam ilegalmente no país.
Do processamento dos dados obtidos por meio da técnica de associação livre de palavras, resultou o somatório $\Sigma=679$, com 66 palavras diferenciadas de todas as palavras evocadas pelo total de participantes da pesquisa ( $n=51$ ). Deste modo, verifica-se, na Figura 1 , o campo diferenciado quanto ao conteúdo das representações e de sua estrutura explicitados pelos participantes da investigação, que ocupam posições simetricamente opostas em função das variáveis sexo e tempo de migração.

O fator 1 (F1 = itálico) explica 66,7\% da variância total das modalidades (palavras-resposta) processadas. O fator 2 (F2 = negrito) explica 15,3\%, perfazendo um total de $82 \%$ da variância total; houve, portanto, parâmetros estatísticos com consistência interna e fidedignidade, tendo em vista pesquisas realizadas no âmbito das representações sociais (Nóbrega \& Coutinho, 2003). Os espaços fatoriais constituídos dos dois primeiros fatores (F1 e F2) e delimitados pelas respostas aos dois estímulos indutores (1= Qualidade de Vida e $2=$ Imigração) revelam a existência de agrupamentos representacionais ou campos semânticos, que evidenciam as similaridades e diferenças nos conteúdos e na estrutura das representações dos participantes (Figura 1).

Observa-se que a Figura 1 destaca com clareza dois campos semânticos configurados em oposição ao fator 1. No eixo à esquerda, encontram-se aglomeradas as representações, que caracterizam o grupo dos imigrantes masculinos; para eles a qualidade de vida (estímulo 1) é representada como alimentação, trabalho, dinheiro e moradia. Com relação ao estímulo 2 (migração), encontram-se nesse mesmo grupo os elementos "dinheiro, trabalho e fuga".

Nesse mesmo fator, no lado direito (em oposição ao grupo masculino), tem-se os campos semânticos das mulheres imigrantes, que representam a qualidade de vida (estímulo 1) na "cultura, saúde, distração e paz"e para o estímulo 2 (migração) os elementos separação, discriminação e partir. O que os diferenciam é que os homens são mais objetivos e as mulheres utilizam mais a subjetividade (bem-estar subjetivo). Esses dados indicam que os participantes do sexo masculino objetivaram a representação da qualidade de vida na obtenção de dinheiro através do trabalho, que propor- 


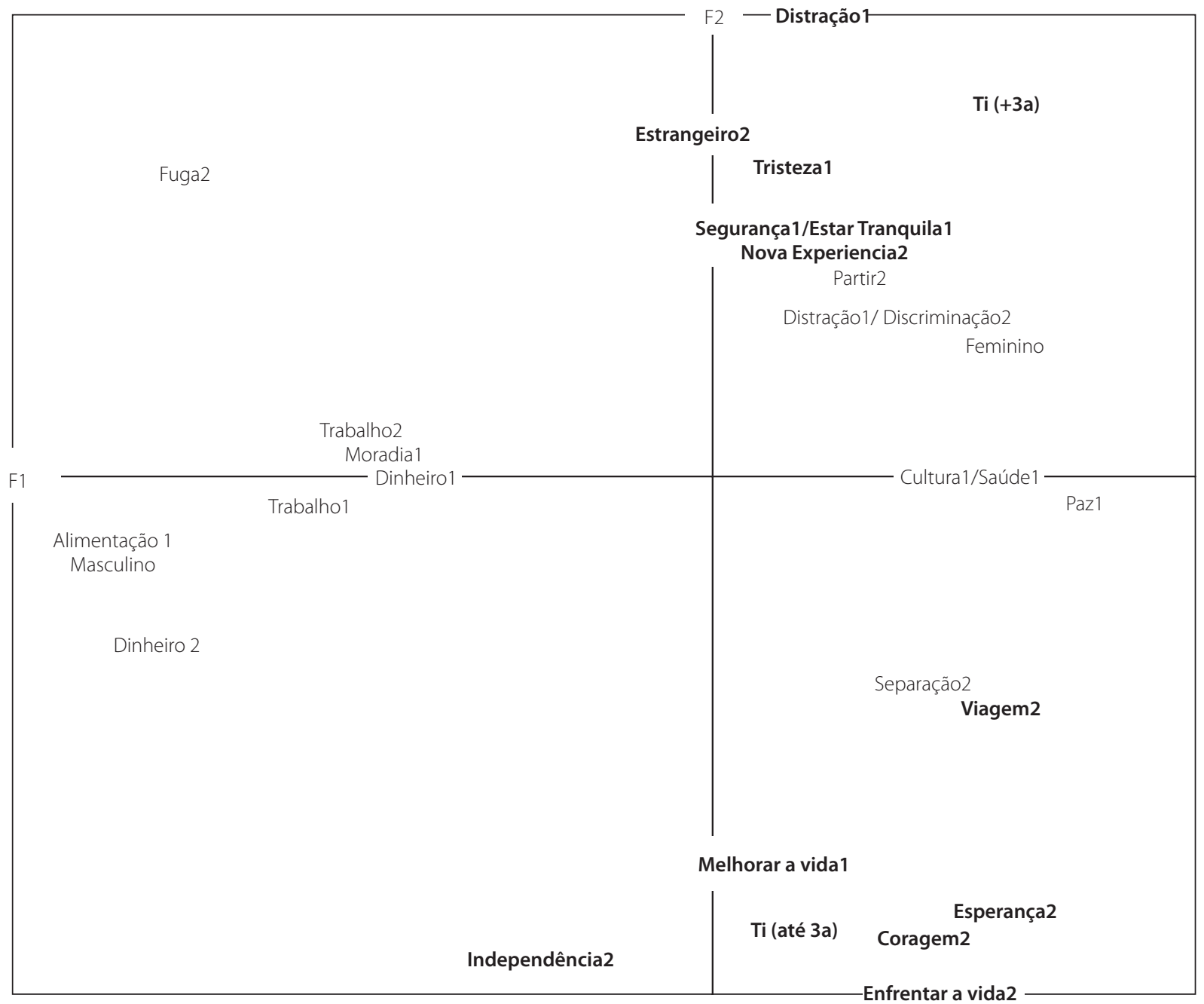

Figura 1. Plano fatorial das representações sociais sobre qualidade de vida de brasileiros imigrantes.

Nota: Ti (+3a) - Tempo de imigração maior que 3 anos; Ti (até 3a) Tempo de imigração até 3 anos.

ciona a aquisição de moradia e alimento; certamente, marcados por seu papel social de provedores, que dita aos homens a responsabilidade sobre as questões mais objetivas da vida. Esses achados são reveladores de vivências de ordem pessoal e social. Vivendo a situação de imigrantes não documentados (73\%), esses participantes enfrentam a ausência contratual, a instabilidade e a inexistência de direitos laborais, situação que os aprisiona, levando-os a ancorar esses construtos em questões básicas de produtividade e sobrevivência.

Pode-se inferir que o trabalho oferece uma estabilidade e credibilidade adquirida perante a sociedade, que acolhe o sujeito por ser um indivíduo produtivo. $\mathrm{O}$ reconhecimento advindo da sociedade escolhida faz

424 com que os migrantes ancorem a qualidade de vida nos fatores psicológico, social, econômico e cultural. Observa-se, ainda, que as associações à expressão "qualidade de vida", realizadas por esses participantes (conforme é possível verificar na Figura 1), estão posicionadas bem próximas ao eixo central, possuindo, portanto, maior força representacional. Os resultados corroboram a definição de qualidade de vida feita por Minayo (2000, p.8), quando refere que este termo"abrange muitos significados, que refletem conheci-mentos, experiências e valores de indivíduos e coletivi-dades, que a ele se reportam em variadas épocas, espa-ços e histórias diferentes; sendo, portanto, uma constru-ção social com a marca da relatividade cultural".

Como se pode visualizar na Figura 1, para os respondentes do sexo feminino a qualidade de vida é, 
sobretudo, cultura, saúde, distração e paz. Verifica-se também que a associação do estímulo qualidade de vida às palavras cultura e saúde está posicionada acima do eixo central, possuindo, portanto, maior força representacional, seguido logo acima pela palavra distração.

Com esses dados pode-se inferir que o grupo feminino residente há mais de três anos (70,3\%) e com situação não documentada (54,1\%) objetiva suas representações em elementos de cunho cultural associados às esferas da saúde, lazer e psicológico, corroborando o conceito holístico da OMS (1985). Pode-se igualmente entender que o grupo feminino encontra, no local de acolhimento, ocupações no mercado de trabalho, mesmo em funções menos qualificadas (domésticas), que propiciam o atendimento de suas necessidades básicas (trabalho, moradia, alimentação); com essas necessidades supridas, essas mulheres associam a qualidade de vida à cultura e ao lazer, diferentemente dos participantes do sexo masculino, que não encontram as mesmas condições de trabalho e habitação no local de acolhimento.

Com relação ao fator F2, na linha vertical (em negrito) encontram-se os campos semânticos dos imigrantes brasileiros de ambos os sexos, que residem em Genebra há mais de três anos ( $\mathrm{Tm}=$ tempo de migração +3a), em oposição aos que residem de um a três anos (Tm = até 3a). Os campos encontram-se, diametralmente, distanciados, o que indica diferenças representacionais.

Na margem superior, localizam-se as representações dos participantes com maior tempo de migração: elas representam qualidade de vida (estímulo 1) como distração, estar tranquila, ter segurança, e para migração (estímulo 2) emergiram os elementos estrangeiro e nova experiência.

Na margem inferior do eixo (F2) encontra-se o grupo de imigrantes com tempo de migração entre um a três anos, cujas representações ao estímulo indutor 1 (qualidade de vida) apresentaram os elementos melhorar de vida, enfrentar a vida. E, para o estímulo indutor 2 (migração), verificam-se os elementos viagem, independência, coragem e esperança.

Entende-se que esse grupo, com menor tempo de migração e ainda em fase de adaptação, vivencia o processo migratório associado a sentimentos de luto, tristeza, saudade em relação ao que foi deixado para trás (amigos, parentes, a terra em que nasceram); questões emocionais dolorosas existentes nos primeiros tempos do processo de aculturação. Como escreve Ramos (2004, p.257), "o processo migratório envolve rupturas espaciais e temporais, nomeadamente mudanças psicológicas, físicas, biológicas, sociais, culturais, familiares, políticas implicando a adaptação psicológica".

Ao comparar as respostas dos dois grupos em relação ao estímulo 1 (qualidade de vida), observaram-se diferenças na objetivação. Para os que vivem há mais de três anos em Genebra e já superaram as primeiras etapas do processo de aculturação (que são a língua, moradia, alimentos, trabalho), a objetivação é feita a partir dos elementos "distração, estar tranquilo e ter segurança", o que não acontece com os participantes com tempo de migração de um a três anos, que objetivaram o estímulo em foco com elementos vinculados à realidade de seu dia a dia (enfrentar a vida, melhorar a vida).

Pode-se compreender que os imigrantes com maior tempo de migração ancoram qualidade de vida nos benefícios do processo migratório, enquanto o outro grupo ancora no vivenciar do processo de aculturação.

Esses resultados corroboram os de Coutinho e Saldanha (2005), quando aludem que os estudos apoiados na perspectiva psicossociológica e nas representações sociais fazem emergir representações não teorizadas ou normatizadas cientificamente, mas que expressam a construção de um conhecimento prático e compartilhado por um determinado grupo de pertença, diretamente relacionado ao contexto social.

\section{Considerações Finais}

A pesquisa coloca em evidência a dialética que se instaura entre os sistemas cognitivos, perceptivos e sociais dos grupos emergentes. Observam-se nos diferentes grupos similitudes e diferenças de conteúdos representacionais, que colocam em destaque uma comunicação e orientação de condutas, de acordo com 
as variáveis sociodemográficas circunscritas, favorecendo sua identidade e comprovando sua função justificadora.

A qualidade de vida foi percebida como algo composto de fatores objetivos e subjetivos. Essa característica foi encontrada também em estudos sobre a subjetividade do bem-estar, que têm demonstrado que não são apenas as condições sociodemográficas (estado civil, idade, sexo, renda, etnia) que definem a sensação de bem-estar sentida pelas pessoas, mas uma combinação de processos subjetivos próprios de cada indivíduo, isto é, as estruturas internas da pessoa ajudam a construir a forma como são percebidos e internalizados os eventos externos, o que reflete na autoavaliação do seu estado de bem-estar e da sua qualidade de vida.

É importante destacar que qualquer experiência vivenciada pelo indivíduo no seu contexto sociocultural afeta de forma significativa seus estados psicoafetivos, emocionais e cognitivos. Nesse entendimento, as representações sobre qualidade de vida e migração, no contexto migratório internacional, não existem enquanto entidades absolutas, isoladas e independentes de sua forma de expressão e manifestação, mas como algo entrelaçado às experiências de cada um dos participantes e vivências de ordem pessoal e social.

Pretendeu-se, com este estudo, contribuir com os conhecimentos já existentes acerca dos construtos "qualidade de vida" e "migração" enquanto fenômenos globais e multidimensionais. Sugere-se a necessidade de novos estudos com a diversificação de instrumentos, ampliação de amostras e espaços culturais.

\section{Referências}

Abric, J-C. (1994). Pratiques sociales et représentations. Paris: Puf.

Annuaire Statistique de la Suisse. (2008). Neuchâtel, Switzerland: Ed. I'Office Fédéral de la Statistique.

Arnold, F. (1995). Migração internacional: quem migra e para onde? Finanças e Desenvolvimento, 10 (2), 46-47.

Auray, J. P., \& Duru, G. (1995). Qualité de vie. In L. Moto (Org.), Santé et mutidisciplinarité: choix et décisions (pp.83-128). Paris: Hermès.

Bonomi, A., Patrick, D., Bushnell, D., \& Martin, M. (2000). Quality of life measurement: will we ever be satisfied? Journal of Clinical Epidemiology, 53 (1), 19-23.
Cibois, P. (1991). L'analyser factorielle (3a.ed.) Paris: Puf. Collection "Que sais-je?"

Coutinho, M. P. L. (2001). Depressão infantil: uma abordagem psicossocial. João Pessoa: Editora Universitária UFPB.

Coutinho, M. P. L., \& Saldanha, A. A. W. (2005). Representações sociais: e práticas de pesquisa. João Pessoa: Universitária UFPB.

Di Giacomo, J. P. (1986). Alliance et rejets intergroupes au seun d'un movement de revendicatin. In W. Doise (Org.), L'etude dês representacions sociales. Paris: Delachaux and Niestlé.

Diener, E., Suh, E., Lucas, R., \& Smith, H. (1999). Subjective well-being: three decades of progress. Psychological Bulletin, 125 (2), 276-302.

Fayers, P. (2000). Quality of life: assessment, analysis and interpretation. Chichester: John Wiley.

Harding, T., Arango, M., Baltasar, J., Climent, C., Ibrahim, H., \& Ladrido, I. (1980). Mental disorders in primary health care: a study of the frequency and diagnosis in four developing contries. Psychological Medicine, 10 (7), 231-242.

Hogo, G. (1998). Migrações internacionais não-documentadas: uma tendência global crescente. Travessia, 9 (30), 5-12.

Jimenes, M. R. (2005). Movimientos migratórios contemporáneos. Murcia: Universidad Católica de San Antonio.

Kanaane, R. (1999). Comportamento humano nas organizações: o homem rumo ao século XXI. São Paulo: Atlas.

Kurtz, M. E., Wyatt, G., \& Kurtz, J. C. (1995). Psycological and sexual well being, philosophical spiritual views, and health habitts of long-term cancer survivors. Health Care Form Women International, 16 (3), 253-262.

Lobo, C., \& Santos, I. (2002). Desenvolvimento e qualidade de vida: a utilização de indicadores sociais. Pensar BH-Política Urbana e Ambiental, 4 (1), 49-50.

Minayo, M. (2000). Qualidade de vida e saúde: um debate necessário. Revista Ciência e Saúde Coletiva, 5 (1),7-18.

Moscovici, S. (1978). Representação social da psicanálise. Rio de Janeiro: Zahar.

Moscovici, S. (2003). Representações sociais. Petrópolis: Vozes.

Nóbrega, S. (2003). Representations sociales de la folie par les familes de malades mentaux au nord-est du Brésil; le cas João Pessoa. Paris: Éditions du Septentrion

Nóbrega, S. M. (2001). Sobre a teoria das representações sociais. In A. S. P. Moreira. Representações social: teoria e prática (pp.55-87). João Pessoa: Editora Universitária UFPB.

Nobrega, S. M., \& Coutinho, M. P. L. (2003). O teste de associação livre de palavras. In M. P. L. Coutinho, A. S. Lima, F. B. Oliveira \& M. L. Fortunato (Orgs.), Representações sociais: abordagem interdisciplinar (pp.67-77). João Pessoa: Editora Universitária UFPB.

Nussbaun, M. (1993). The quality of life. Oxford: Clarendon Press. 
Optical Fibre Sensors. (2008). International Conference on Optical Fibre Sensors. Western Australia, Australia.

Organisation de Coopération et de Développement Économiques. (2005). Fostering devolopment in a global economy. Paris: OCDE.

Paschoal, S. (2000). Qualidade de vida do idoso: elaboração de um instrumento que privilegia a sua opinião. Dissertação de mestrado não-publicada, Faculdade de Medicina, Universidade de São Paulo.

Ramos, N. (2004). Psicologia clínica e da Saúde. Lisboa: Universidade Aberta.

Seabra, P. (2003). Percursos migratórios de imigrantes brasileiros e do leste europeu em Portugal. Dissertação de mestrado não-publicada, Universidade Aberta, Lisboa, Portugal.

Sebe, J. C. (2004). Brasil fora de si: a saga dos brasileiros na América. São Paulo: Parábola.

Setién, M. (1993). Indicadores sociales de calidad de vida. Madrid: Sieglo Vintiuno.
Systeme D'Observation Permanente des Migrations International. (2008). OECD Organisation for Economic Co-operation and Development. Trends in International Migration Éditions OECD. Paris.

The United Nations Population Fund. (2007). Misson report. New York. Retrieved February 16, 2007, from www. unfpa. org

Vala, J., \& Monteiro, M. (2005). Psicologia social. Lisboa: Fundação Calouste Gulbenkian.

Witier, P. (1997). Lá Qualité de vie. Revue Prevenir, 33 (2), 61-62.

World Health Organization. (2002). Enfermities Full Attention Manual Prevailing of Childhood (AIEPI) and for Studeats. Preliminal version. Washington, D.C.: Author.

Recebido em: 6/8/2007

Versão final reapresentada em: 24/4/2009

Aprovado em: 26/5/2009 